\title{
LAS ESTAFAS PIRAMIDALES EN COLOMBIA: SU TRATAMIENTO EN LA LEY 1700 DE 2013 Y EN EL DECRETO 024 DE 2016*
}

\author{
Pyramid schemes in Colombia: its treatment in Law 1700 of \\ 2013 and in Decree 024 of 2016
}

\author{
Golpes de pirâmide na Colômbia: seu tratamento na Lei 1700 \\ de 2013 e no Decreto 024 de 2016
}

Miguel Ángel Fernández-Salinero San Martín
miguel-fssmn@icam.es

Fecha de recepción: 15 de agosto de 2019 Fecha de revisión: 20 de agosto de 2019 Fecha de aceptación: 28 de agosto de 2019

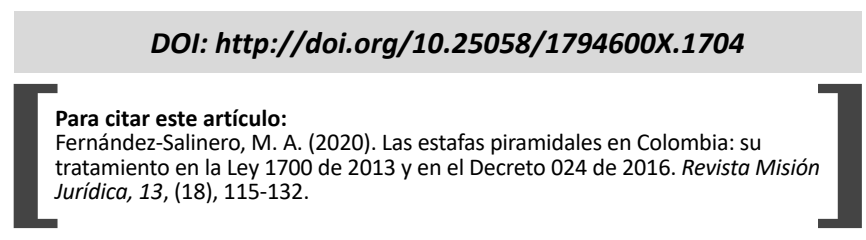

\section{RESUMEN}

El artículo tiene como objetivo principal dar a conocer, como ejemplo para los legisladores del resto del mundo, las notas esenciales del tratamiento jurídico legislativo que la República de Colombia otorga a las actividades de venta directa multinivel, o de mercadeo en red, si se prefiere utilizar una nomenclatura "más colombiana", la cual sirve de barrera para evitar el vacío legal que en otros países beneficia, potencia y, muchas veces, promueve que la alta delincuencia económica establezca las bases centrales de esquemas piramidales en fronteras donde no existe legislación alguna sobre la materia. Esto trae consigo la ruina de miles de pequeños y medianos ahorradores, que depositan sus esperanzas económicas en esquemas piramidales disfrazados, al socaire, de una falsa legalidad.

Finalmente, se analizan los fenómenos de estafa piramidal que se cometen utilizando criptomonedas como por ejemplo el bitcóin, haciendo un recorrido por el régimen jurídico y fiscal de las criptodivisas y finalmente ocupándose de algunos casos tristemente célebres de estafas piramidales que se han cometido utilizando a las criptomonedas como medio de pago o de inversión.

\footnotetext{
* El presente estudio es el resultado por un lado de los conocimientos adquiridos en la práctica profesional y forense como Abogado en casos de acusación (colectiva e individual) y defensa, en causas seguidas por los delitos de estafa piramidal, y, de otro lado en el estudio de manuales, leyes y Sentencias de distintos países en la materia. En el caso concreto ha resultado determinante el estudio de la Ley 1700 de 23 de diciembrey del Decreto 024, de 12 de enero.

a. Letrado y profesor universitario especialista en Derecho mercantil, en sentido amplio, y en el sector específico del Derecho penal económico. Cuenta con más de una década de experiencia en la dirección técnica, representación y defensa jurídico procesal en asuntos penales relacionados con el tipo penal de estafa (incluidas las denominadas estafas piramidales y "ripdeal"), blanqueo de capitales, insolvencias punibles, delitos fiscales y delitos cometidos por personas jurídicas. Autor de numerosas publicaciones y trabajos de investigación, conferencista internacional.
} 


\section{PALABRAS CLAVE}

Estafas piramidales; esquema Ponzi; Ley 1700 de 2013; Decreto 024 de 2016, criptomoneda, bitcóin.

\section{ABSTRACT}

The purpose of this article is to show, for example to legislators across the world, the essential notes on the juridical legislative treatment that the Republic of Colombia has on Multi-level Direct Selling or network marketing, as it is most commonly referred to in the "Colombian way". This provides a barrier to avoid the legal gap that in other countries benefit, boost and, oftenly allow high level economic delinquents to establish the central bases of pyramid schemes in places where legislation on the matter does not exist. This leads to the ruin of thousands of small and medium scale savers that put their economic hopes in disguised pyramid schemes, under the guise of a false legality.

Finally, the phenomenon of pyramid scheme frauds that are commited using cryptocurrency as bitcoin will be analyzed, covering the juridical and tax regime of cryptocurrency and, in the end, describing infamous cases of pyramid scams that have been commited utilizing this type of currency as a means of payment or investment.

\section{KEYWORD}

Pyramid scheme fraud; Ponzi scheme; Law 1700 of 2013; Decree 024 of 2016; cryptocurrency; bitcoin.

\section{RESUMO}

0 principal objetivo do artigo é divulgar, como exemplo aos legisladores do resto do mundo, as notas essenciais do tratamento jurídico legislativo que a República da Colômbia concede às atividades de vendas diretas multiníveis ou marketing de rede, se preferir uma nomenclatura "mais colombiana", que serve como uma barreira para evitar o vácuo legal que em outros países beneficia, fortalece e, muitas vezes, promove que altos crimes econômicos estabelecem as bases centrais dos esquemas de pirâmide nas fronteiras onde não há legislação sobre o assunto. Isso traz consigo a ruína de milhares de poupadores pequenos e médios, que depositam suas esperanças econômicas em esquemas de pirâmides disfarçados, sob o sol, de falsa legalidade.

Finalmente, analisamos os fenômenos de golpes de pirâmide que são cometidos usando criptomoedas como bitcoin, fazendo um tour pelo regime legal e fiscal das criptomoedas e finalmente lidando com alguns casos infames de golpes de pirâmide que foram cometidos usando criptomoedas como meio de pagamento ou investimento.

\section{PALAVRAS-CHAVES}

Golpes de pirâmide; Esquema Ponzi; Lei 1700 de 2013; Decreto 024 de 2016, criptomoeda, bitcoin.

\section{INTRODUCCIÓN}

Auspiciada por un acontecimiento tristemente célebre para Colombia, acaecido en la primera década del siglo XXI, el cual se vino a denominar como "la crisis de las pirámides"1, se expidió la Ley 1700 de 2013, por medio de la cual se reglamentan las actividades de comercialización en red o mercadeo multinivel, la cual encuentra su desarrollo en el posterior Decreto 024 de 2016, del Ministerio de Comercio, Industria y Turismo colombiano ${ }^{2}$.

Así las cosas, esta pléyade legislativa puede y debe ser un ejemplo normativo para el resto de los países del mundo, puesto que otorga un tratamiento jurídico y legislativo adecuado a la actividad del Marketing multinivel o, si se prefiere utilizar una nomenclatura más colombiana, "mercadeo en red", que viene a ser sin duda un sector que tradicionalmente se ha visto arropado por la tentación que representan los esquemas piramidales por la facilidad que estos prometen de obtener ilícitamente pingües beneficios bajo

1. En Colombia se viene a denominar como la crisis de las pirámides al fenómeno de la proliferación y ulterior quiebra de sistemas empresariales de venta directa que tuvo lugar en Colombia a partir del año 2008, y que, acusados por las autoridades colombianas de actividades ilegales tales como esquemas piramidales, captación ilegal de dinero y blanqueo de capitales, y que desembocó en la intervención de los mismos por parte de las autoridades estatales, y en el procesamiento de sus máximos responsables.

2. El cual adiciona un capítulo al título 2 de la parte 2 del libro 2 del Decreto Único Reglamentario del Sector Comercio, Industria y Turismo, número 1074 de 2015, y se dictan otras disposiciones. 
la falsa promesa de bonanza o independencia económica.

Las estafas y fraudes piramidales constituyen, desde su comienzo hasta su final, una vía criminal o "itercriminis" a través de la cual la alta delincuencia causa estragos económicos y, muchas veces, psicológicos, en el sector de los pequeños y medianos ahorradores, colectivo mayoritariamente afectado por estas conductas criminales deleznables e inicuas ${ }^{3}$.

\section{ANTECEDENTES HISTORICOS EN COLOMBIA: EL CASO HOLDING D.M.G. S.A.}

En Colombia se volvió tristemente famoso un caso de estafa piramidal mundialmente conocido como "D.M.G.", el cual debe su nombre a las iniciales de su máximo responsable, David Murcia Guzmán, al socaire de la sociedad mercantil denominada "Grupo DMG S.A.", constituida en 2005 en Bogotá.

El modelo de negocio de este entramado encontraba su señuelo en dos elementos: (i). Las Tarjetas Prepago y (ii). Los contratos de publicidad.

Para poder ser cliente y comprar a través del modelo D.M.G., cada cliente debía adquirir al menos dos tarjetas prepago muy similares a las que se utilizan de ordinario en el comercio, pero con la particularidad que, cuando el cliente adquiría y activaba las tarjetas de D.M.G., estaba firmando un contrato con la mercantil denominada Global Marketing Colombia S.A., en cuya virtud se comprometía a prestar "servicios como activador de marcas y promotor de publicidad personalizada para activación de diferentes marcas que maneje o manejare el contratante". Curiosamente, los clientes nunca recibían copia de los citados contratos.

El modelo de negocio D.M.G. HOLDING S.A., siguiendo alguno de los estudios serios en la materia

(...) utilizaba un esquema multinivel que impulsaba otras marcas a través de ellos; el nuevo socio o cliente lo que hacía era cargar dos tarjetas prepago,

3. Para el lector que desee profundizar sobre el presente tema, ver del autor Fernández-Salinero (2019). una por valor de $\$ 10.000$ que se denominaba "tarjeta de puntos", a la cual se le cargaba hasta un millón de puntos por pago de publicidad voz a voz, que respaldaba un contrato firmado entre las partes, donde el cliente o socio se comprometía a no hablar mal de la empresa y a traer nuevos socios (este millón de puntos se traduce al común como $100 \%$ de intereses), la otra tarjeta se cargaba con el valor que el cliente quisiera depositar, desde $\$ 100.000$ hasta $\$ 50.000 .000$. El cliente podía adquirir todo tipo de bienes y servicios, desde ropa o artículos para el hogar, hasta carros y viajes de turismo a nivel mundial, por medio de un contrato que aplicaba en dos modalidades: a) a seis meses, durante los cuales no se podía retirar el dinero, una vez pasado el lapso podía retirar el capital más los puntos por publicidad generados en este tiempo, que sumaban el doble de lo aportado; claro está que el capital se retiraba completo siempre y cuando no hubiera hecho uso de la tarjeta. Hago una aclaración: se podía retirar el dinero antes de los seis meses pero se perdía el derecho a reclamar cualquier tipo de puntos, sin embargo el capital sería devuelto en su totalidad. b) A cinco meses, mediante el cual, dependiendo del monto, el nuevo socio podía reclamar mensualmente hasta 100.000 puntos por publicidad, es decir el $10 \%$ de lo depositado (Diaz, 2014: 260).

Según Bedoya (2009), el entramado D.M.G. logró captar alrededor de 36 millones de dólares de los Estados Unidos (USD), aproximadamente, llegando a afectar a unas 200.000 personas que invirtieron su dinero en el citado esquema piramidal.

(...) algunas de las personas que entregaron su dinero a D.M.G. recibieron cumplidamente el dinero prometido, sin embargo y como lo demuestran múltiples estudios económicos este esquema piramidal es inviable. Por ello, y a pesar de que muchas de las personas que entregaron su dinero a DMG no sufrieron pérdidas, esta es una actividad que plasma el riesgo creado en el resultado. Sea por los tantos que perdieron su patrimonio, y se encuentran inmersos en un proceso de reparación a víctimas; o por los que simplemente tuvieron suerte y recibieron cuantiosas ganancias por dicha actividad (Álvarez, 2017).

Para cerrar cabe destacar que D.M.G. no funcionaba bajo un esquema tan simple como el de solo pagar intereses con el dinero que ingresaba de los nuevos clientes. DMG contaba 
con todo un esquema empresarial, en sus múltiples establecimientos comerciales los miembros podían adquirir bienes muebles de diversas clases como rédito al dinero entregado. Igualmente el ingreso de capitales ilícitos hacía parte del acontecer empresarial de DMG. Todos estos factores hicieron que dicha empresa no defraudara a la mayoría de sus clientes, muchos de los cuales se manifestaron en defensa de la misma una vez se inició la intervención estatal de aquella.

\section{2. "BIS". OTROS ANTECEDENTES HISTORICOS DE ESTAFAS PIRAMIDALES}

\subsection{CASO SPITZEDER}

En la historia económica se cita el banco "Spitzeder" en 1869 como la primera estructura piramidal. En este caso el dinero de los impositores, que era retribuido con el $10 \%$, no se invertía y se destinaba, junto al que aportaban nuevos clientes, a reintegrar el capital y abonar los intereses devengados a favor de los inversionistas más antiguos.

\subsection{CASO PONZI}

La denominación primigenia de la estafa piramidal se conoce como "esquema Ponzi", debiendo su nombre al italiano afincado en los Estados Unidos de América, Carlo Ponzi, quien en la segunda década del siglo XX fue autor de una estafa que alcanzó mayor repercusión sin precedentes en la historia.

Carlo Ponzi era un emigrante italiano que desembarcó en los Estados Unidos alrededor de la década de 1920. De clase baja y muy escasos recursos, como la mayor parte de inmigrantes que llegaban a dicho país, al poco tiempo de llegar a América se percató, gracias a un correo que recibió de Italia, de que los cupones de respuesta internacional de correos eran susceptibles de ser vendidos en los Estados Unidos a precios más caros que en cualquier país extranjero, por lo que estas transacciones terminarían por producir ganancias. Así las cosas, tras esparcirse el rumor, muchos inversores decidieron no quedarse fuera del negocio y apoyaron a Ponzi con capital.

Pero aunque Carlo Ponzi estuviera recogiendo abrumadoras sumas de dinero y la gente hiciera colas para confiarle sus ahorros, en realidad éste último no estaba comprando los cupones, sino que estaba pagando beneficios de hasta el $100 \%$ en tres meses utilizando el capital de los sucesivos nuevos inversionistas. Esa es la esencia de los sistemas piramidales en general y del sistema de Ponzi en particular.

En su afán de hacer negocio y lucrarse, Ponzi convenció a amigos y asociados de que apoyaran su sistema en un principio, ofreciendo un retorno del $50 \%$ en una inversión en 45 días. Algunas personas invirtieron y luego obtuvieron lo prometido en el lapso que se había acordado. La noticia se empezó a esparcir, y el promedio de inversiones comenzó a crecer.

Ponzi contrató agentes y pagó generosas comisiones por cada dólar que pudieran traer. En febrero de 1920, obtuvo una cantidad de dólares de los Estados Unidos de América (USD) equivalente a unos 60.000 USD al tipo de cambio de 2019. En marzo ya tenía unos 300.000 USD.

La histeria masiva se estaba construyendo y Ponzi comenzó a expandirse a Nueva Inglaterra y Nueva Jersey. En su tiempo los que invertían obtenían grandes beneficios, y estos inversores regaban la noticia y motivaban a otros a invertir.

Para mayo de 1920, Ponzi había logrado recaudar unos 420.000 USD, y comenzó a depositar este dinero en el Hanover Trust Bank of Boston (un pequeño banco ítalo -estadounidense en la calle de Hanover, al norte de la calle italiana). $\mathrm{Su}$ aspiración era que a lo largo del tiempo se pudiera convertir en el presidente del banco o pudiera imponer sus decisiones sobre este, llegando de facto a controlar el banco al comprar sus acciones.

En julio de 1920 ya tenía millones. Muchas personas vendían o hipotecaban sus casas con la esperanza de lograr altos intereses. El 26 de ese mes gran parte del plan comenzó a hundirse, después de que el periódico Boston Post cuestionara las prácticas de la empresa de Ponzi. Finalmente la empresa fue intervenida por el gobierno de los Estados Unidos de América, que detuvo todas las nuevas captaciones de dinero.

Muchos de los inversores reclamaron enfurecidos su dinero, momento en el cual Ponzi les devolvió su capital a aquellos que lo solicitaron, 
lo que causó un aumento considerable en el apoyo popular hacia él, ya que muchos le sus inversores le proponían que se adentrara a la política. El emporio y los sueños de Ponzi crecieron, aún más porque planeaba manejar un nuevo tipo de banco, en el cual las ganancias se repartieran por igual entre los accionistas y aquellos que ingresaran dinero en el banco. Hasta planeó reabrir su empresa bajo un nuevo nombre "Charles Ponzi Company", cuyo principal objetivo era invertir en empresas alrededor del mundo.

Gracias a este esquema, Ponzi comenzó a vivir una vida llena de lujos: compró una mansión con aire acondicionado y un calentador para su piscina, y además trajo a su madre de Italia en primera clase. Muy pronto este inmigrante de bajos recursos obtuvo no solo una gran cantidad de dinero sino que se colmó de los lujos más extravagantes.

En agosto de 1920 los bancos y medios de comunicación declararon a Ponzi en bancarrota.

Años después de ser descubierto el entramado piramidal de Ponzi, él mismo confesó que en 1908 había sido partícipe de una estafa muy similar en Canadá, que ofrecía a los inversores grandes beneficios.

El gobierno federal de los Estados Unidos intervino finalmente a Ponzi y, descubierta su estafa, fue enviado a la cárcel pero tuvo que ser liberado ya que pagó su fianza en dos prisiones distintas y decidió continuar con su sistema, convencido de que lo podía sostener. Muy pronto el sistema cayó y los ahorradores perdieron su dinero.

Ponzi, aunque fue deportado a su Italia natal y a pesar de que se descubrió por completo su estafa, la cual dejó en la ruina a cientos de familias, fue aclamado por muchos como un benefactor.

\subsection{CASO MADOFF}

Nos encontramos ante otro exponente histórico de estafa piramidal, ideada en este caso por el inmigrante italiano en los EE.UU., Agustín Vidal, en los años veinte. En el Caso Madoff, se llegaron a captar inversiones por valor de entre 50.000 y 65.000 millones de dólares (lo destacado fue, no tanto el número de inversores perjudicados, sino el volumen económico del perjuicio, que afectó incluso a algunas economías nacionales) encontrándose entre los perjudicados personas públicamente reconocidas e importantes entidades financieras y filantrópicas de todo el mundo (en España, entre otros, el Banco de Santander, y BBVA).

La estafa se basaba en una información incompleta, además de engañosa, de los productos que ofrecía y de las altas rentabilidades que producían, el acceso a la misma era casi imposible ya que aquel se encargaba de que no saliera a la luz aquello que consideraba estrictamente confidencial y que pudiera poner en peligro su negocio, como el método que utilizaba para gestionar el fondo, lo que unido al exceso de confianza de los inversores, les llevaba a no cotejar aquella, en especial sus estados financieros, o la validez de los certificados de inversión.

El binomio confianza-información falsa, resulta determinante en este tipo de actuaciones, que lleva a los perjudicados a no cuestionarse la veracidad de los datos contenidos en los documentos que llegan a su conocimiento. Esta certidumbre, en el caso Madoff llegaba a extremos insospechados, sobre todo por ser uno de los fundadores y director durante tres años de la "National Association of Securities Dealers Automated Quotation" (NASDAQ) la segunda bolsa de valores más importante de los Estados Unidos, estando además muy bien relacionado con su organismo regulador "Security Exchange Comisión".

\section{DEFINICIÓN DE ESTAFA PIRAMIDAL}

Por su claridad y concisión, se considera adecuado acudir a la jurisprudencia española en orden a transcribir una definición de estafa piramidal y, a este respecto, la Sentencia de Audiencia Nacional de 09/03/2017, ofrece en su Fundamento de Derecho Cuarto una definición del tipo penal de estafa piramidal:

(...) se ha venido considerando como estafa piramidal aquellas conductas en que el autor se dedica a captar capital prometiendo la realización de importantes inversiones por medio de alguna entidad mercantil previamente constituida que sirve de señuelo. Se promete a los posibles clientes el abono de sustanciosos intereses, sin que después existan los negocios que habrían de producir los ingresos que permitirían devolver el capital y los intereses convenidos. Lo habitual es que 
en una primera etapa se abonen a los primeros inversores el capital y los intereses valiéndose de las aportaciones de los sucesivos clientes. En estas conductas delictivas 'piramidales o en cascada' los sujetos realizan una puesta en escena en ejecución de un designio criminal único encaminada a defraudar a un número indeterminado de personas, pudiendo proyectarse esta acción defraudatoria sobre una persona que a su vez convenza a otras, como consecuencia de su propio engaño, a realizar similares inversiones. Este modelo piramidal de estafa conduce necesariamente a la frustración del negocio prometido, pues en la medida en que se incrementa el capital recibido, aumentan exponencialmente las necesidades de nuevos ingresos para abonar los intereses, hasta que el actor deja de pagarlos y se apropia definitivamente de los capitales fraudulentamente recibidos (STS $900 / 2014$, de 26 de diciembre).

La definición no deja lugar a dudas de que se trata de un tipo específico de estafa que debería recibir un tratamiento concreto en nuestro Código Penal, ya que la conductas criminales piramidales se encuentran recubiertas de una serie de elementos objetivos y subjetivos muy específicos, que suelen afectar a un número elevado de personas.

Partiendo de la definición jurisprudencial de estafa piramidal que acabamos de transcribir "ut supra", los elementos específicos de este tipo penal son los siguientes:

a). Una conducta empresarial de captación de capitales, bajo cualquier modalidad ya sea un producto financiero, depósitos bancarios, de mercado filatélico (Caso Afinsa) o, en otros casos, la inversión en el mercado de divisas y ello con independencia de que se trate de un negocio multinivel (multilevel marketing) aunque en este tipo de negocios lo que se buscan son clientes para invertir en un producto concreto y tangible, más que inversores y que viene regulado en la Ley $7 / 1996$, de 15 de enero, de Ordenación del Comercio Minorista.

b). Ausencia de inversiones relevantes para obtener rendimiento de los capitales recibidos de los clientes.

c). Pago de las deudas contraídas con los clientes, para el reintegro o reembolso del capital más los intereses, que se realiza con el mismo dinero depositado por estos o con el dinero aportado por nuevos clientes, es decir mediante tesorería, sistema insostenible a largo plazo.

d). Negocio que carece de sentido económico, que lleva implícito su fracaso o colapso, porque el crecimiento de la actividad empresarial aumenta las pérdidas. Los inversores antiguos son pagados con el dinero de los nuevos, y en el momento que el capital que aportan los nuevos "entrantes" no cubra los intereses que hay que pagar a aquellos, el sistema quiebra y el fraude sale a la luz, dado que resulta imposible de mantener a largo plazo.

Por supuesto, la publicidad agresiva $y$ engañosa, es una nota fundamental $y$ característica en estos sistemas piramidales, que ofrecen unos productos muy atractivos, con alta rentabilidad, y con cierto riesgo que tratan de paliar con otro tipo de inversiones o de regalos de bienes tangibles como vehículos, viajes, relojes, ordenadores portátiles, smartphones, entre otros "premios" o "rewards".

\section{EL TRATAMIENTO DE MARKETING MULTINIVEL EN LA LEY 1700 DE 27 DE DICIEMBRE DE 2013}

Tradicionalmente los esquemas empresariales de venta directa multinivel han estado velados por el estigma de la denominación unas veces de esquema piramidal y de esquema ponzi, otras de esquemas fraudulentos que, mediando engaño y valiéndose de una estructura ilícita piramidal han arruinado a no pocas familias a lo largo de la geografía mundial.

Debe matizarse que existen sistemas empresariales o, si se prefiere, modelos de negocio de venta directa que no son piramidales, aunque, eso sí, como ya se describió, a lo largo de la historia no han sido escasas las estafas piramidales que han cubierto de tragedia económica las páginas de los diarios globales.

Como apuntó FERNANDEZ-SALINERO (2019), a diferencia de otros países ${ }^{4}$, en España no existe

4. En la República de Colombia la materia que nos ocupa se encuentra regulada por la Ley 1700 de 27 de diciembre de 2013 por medio de la cual se reglamentan las actividades de comercialización en red o mercadeo multinivel, la cual encuentra su desarrollo en el posterior Decreto 024 de 12 de enero de 2016, del Ministerio de Comercio, Industria y Turismo colombiano, el cual adiciona un capítulo al título 2 de la parte 2 del libro 2 del Decreto Único Reglamentario del Sector Comercio, 
ninguna disposición legal concreta que regule la actividad empresarial denominada "marketing multinivel", por lo que resulta necesario centrar ahora la atención, a efectos ilustrativos, en las únicas disposiciones normativas que regulan la reseñada materia.

1.- El primero de los preceptos que regulan la materia del marketing multinivel en España se encuentra en el Título II, Capítulo I de la Ley $7 / 1996$, de 15 de enero, de ordenación del comercio minorista, concretamente en los artículos 22 y 23, que disponen literalmente lo siguiente:

\section{Artículo 22. Venta multinivel}

1. La venta multinivel constituye una forma especial de comercio en la que un fabricante o un comerciante mayorista vende sus bienes o servicios a través de una red de comerciantes y/o agentes distribuidores independientes, pero coordinados dentro de una misma red comercial y cuyos beneficios económicos se obtienen mediante un único margen sobre el precio de venta al público, que se distribuye mediante la percepción de porcentajes variables sobre el total de la facturación generada por el conjunto de los vendedores integrados en la red comercial, y proporcionalmente al volumen de negocio que cada componente haya creado. A efectos de lo dispuesto en este artículo, los comerciantes y los agentes distribuidores independientes se considerarán en todo caso empresarios a los efectos previstos en el texto refundido de la Ley General para la Defensa de los Consumidores y Usuarios y otras leyes complementarias.

2. Queda prohibido organizar la comercialización de bienes y servicios cuando:

a) Constituya un acto desleal con los consumidores conforme a lo previsto en el artículo 26 de la Ley 3/1991, de 10 de enero, de Competencia Desleal.

b) No se garantice adecuadamente que los distribuidores cuenten con la oportuna contratación laboral o cumplan con los requisitos que vienen exigidos legalmente para el desarrollo de una actividad comercial.

Industria y Turismo, número 1074 de 2015, y se dictan otras disposiciones. c) Exista la obligación de realizar una compra mínima de los productos distribuidos por parte de los nuevos vendedores, sin pacto de recompra en las mismas condiciones.

4. En ningún caso el fabricante o mayorista titular de la red podrá condicionar el acceso a la misma al abono de una cuota o canon de entrada que no sea equivalente a los productos y material promocional, informativo o formativo entregados a un precio similar al de otros homólogos existentes en el mercado y que no podrán superar la cantidad que se determine reglamentariamente.

En los supuestos en que exista un pacto de recompra, los productos se tendrán que admitir a devolución siempre que su estado no impida claramente su posterior comercialización.

Artículo 23 Prohibición de ventas en pirámide

Son prácticas de venta piramidal las previstas en el artículo 24 de la Ley 3/1991, de 10 de enero, de Competencia Desleal, siendo nulas de pleno derecho las condiciones contractuales contrarias a lo dispuesto en dicho precepto (Jefatura del Estado, 1996).

2.- El segundo precepto que regula la actividad empresarial del marketing multinivel es España es el artículo 24 de la Ley 3/1991, de 10 de enero, de Competencia Desleal, que dispone literalmente lo siguiente:

Artículo 24 Prácticas de venta piramidal

Se considera desleal por engañoso, en cualquier circunstancia, crear, dirigir o promocionar un plan de venta piramidal en el que el consumidor o usuario realice una contraprestación a cambio de la oportunidad de recibir una compensación derivada fundamentalmente de la entrada de otros consumidores o usuarios en el plan, y no de la venta o suministro de bienes o servicios (Jefatura del Estado, 1991) ${ }^{5}$.

Así las cosas, podemos pues admitir sin ambages que no existe en España un desarrollo legal ni reglamentario que regule el marketing

5. Las anteriores disposiciones legales han sido redactadas por el apartado 11 del artículo primero de la Ley 29/2009, de 30 de diciembre, por la que se modifica el régimen lega de la competencia desleal y de la publicidad para la mejora de la protección de los consumidores y usuarios («B.O.E.»31 diciembre), con vigencia desde le día 1 enero 2010. 
multinivel, lo cual no puede ser motivo de orgullo. El elevado número de estafas piramidales que se gestan y desarrollan en España, contrasta con la inexistencia de una ley que regule los requisitos de desarrollo y ejercicio de las actividades empresariales de venta directa multinivel en cualquiera de sus modalidades.

Pues bien, en Colombia el estado de la cuestión es muy distinto, el legislador colombiano ha sido consciente de la necesidad y conveniencia de la existencia de una legislación específica que regule el sector del mercadeo en red (sistema de venta directa multinivel), que evite vacíos legales donde puedan ampararse los delincuentes económicos. Por tal motivo ha promulgado la Ley 1700 de 27 de diciembre de 2013, por medio de la cual se reglamentan las actividades de comercialización en red o mercadeo multinivel.

\subsection{DEFINICÓN DE MARKETING MULTINIVEL O MERCADEO EN RED}

La citada Ley 1700 de 2013, en su artículo 2 ofrece una acertada definición de lo que se entenderá constituye actividad multinivel, la cual será "toda actividad organizada de mercadeo, de promoción, o de ventas, en la que confluyan los siguientes elementos":

1. la búsqueda o la incorporación de personas naturales, para que estas a su vez incorporen a otras personas naturales, con el fin último de vender determinados bienes o servicios.

2. El pago, o la obtención de compensaciones $u$ otros beneficios de cualquier índole, por la venta de bienes y servicios a través de las personas incorporadas, y/o las ganancias a través de descuentos sobre el precio de venta.

3. la coordinación, dentro de una misma red comercial, de las personas incorporadas para la respectiva actividad multinivel (Congreso de la República de Colombia, 2013).

Quizá el artículo 1 adolece de una definición directa de lo que es el mercadeo en red, puesto que se limita a enumerar una serie de elementos que deben confluir en las "actividades organizadas de mercadeo".

\subsection{DE LA NECESIDAD DE LAS EMPRESAS DE MERCADEO EN RED DE}

\section{TENER OFICINA ABIERTA PERMANENTE} AL PÚBLICO

En ese sentido, el parágrafo 1 de la Ley 1700 de 2013, plantea que:

(...) las compañías que ofrezcan bienes o servicios en Colombia a través del mercadeo multinivel deberán establecerse con el lleno de los requisitos legales contemplados en la ley vigente y tener como mínimo una oficina abierta al público de manera permanente. En los casos en que esta actividad se realice a través de un representante comercial, este último deberá permanente y será el responsable del cumplimiento de las normas establecidas en la normativa colombiana para las actividades, productos y servicios ofrecidos (Congreso de la República de Colombia, 2013).

\subsection{DE LOS REQUISITOS MÍNIMOS DE LOS PLANES DE COMPENSACIÓN}

Dispone el artículo 6 de la Ley 1700 de 2013, que

(...) para efectos de la presente ley, las estipulaciones que se refieran al pago, yen general a las recompensas que sean ofrecidas a los vendedores independientes por parte de las compañías multinivel, se denominarán planes de compensación. Igualmente se entenderá que 'las estipulaciones que regulen los rangos o cualquier otro cambio de la situación de los vendedores independientes dentro de la respectiva red comercial, harán parte de estos planes de compensación.

En los planes de compensación deberán expresarse con claridad los porcentajes de recompensa o pagos ofrecidos; los eventos o logros que darán lugar a los premios o bonos económicos que se ofrezcan a los vendedores independientes; los nombres, íconos u objetos físicos y privilegios a ganar por los vendedores independientes dentro del esquema de ascensos establecidos en el plan; los requisitos en volumen, de productos o dinero, de vinculación de nuevos vendedores independientes y logro de descendencia, tenida como tal la cadena a través de la cual un nuevo distribuidor vincula a otro, este a otro y así sucesivamente, para acceder a los rangos, premios y reconocimientos.

Ningún plan de compensación podrá consistir en el disfrute de créditos en puntos, o derechos de reconsumo de los productos o servicios ' promovidos, en más allá del cincuenta por ciento (50\%) de su alcance o cubrimiento, y cuando las 
compensaciones previstas en el respectivo plan consistan total o parcialmente en estos, el vendedor independiente es libre de rechazarlos (Congreso de la República de Colombia, 2013).

Esta disposición normativa viene a ser toda una declaración de principios que supone de "iure" una prohibición de ventas piramidales o en cascada, recogida legalmente de forma expresa a diferencia de lo que sucede en otros muchos países.

\subsection{DE LA SUPERINTENDENCIA DE SOCIEDADES COMO ENTIDAD DE INSPECCIÓN, VIGILANCIA Y CONTROL DE LAS EMPRESAS DE MERCADEO EN RED}

La ley en análisis determina que, sin perjuicio de las funciones que correspondan a otras entidades del Estado respecto de las compañías multinivel, su actividad como tal será vigilada por la Superintendencia de Sociedades. Lo anterior con el fin de prevenir y, si es del caso sancionar, el ejercicio irregular o indebido de dicha actividad. Igualmente la encarga de asegurar el cumplimento de lo prescrito en la normatividad vigente y en las normas que la modifiquen o complementen.

La Superintendencia de Sociedades será competente para realizar la vigilancia y control de las compañías multinivel y sus actividades, y ejercerá estas funciones de acuerdo con sus competencias legales vigentes y con las demás disposiciones aplicables de esta ley.

Parágrafo: La Superintendencia de Sociedades podrá solicitar conceptos técnicos relacionados con bienes y servicios comercializados y/o promovidos bajo el esquema multinivel, con el fin de establecer si estos corresponden a los bienes o servicios respecto de los cuales está prohibido ejercer actividades multinivel, o para verificar si existe o no una verdadera campaña de publicidad. La Superintendencia Financiera de Colombia, la Superintendencia de Industria y Comercio, el Invima y el Viceministerio de Turismo en forma preferente y en lo que les corresponda de acuerdo a las normas vigentes, tendrán competencia para emitir estos conceptos.

En todo caso, la determinación sobre si una actividad o conjunto de actividades comerciales específicas constituyen actividades multinivel, y sobre la verdadera naturaleza de los distintos bienes o servicios que se promocionen mediante dichas actividades, quedará en cabeza de la Superintendencia de Sociedades (Congreso de la República de Colombia, 2013, art.7).

En lo atinente a las facultades de la Superintendencia de Sociedades, el artículo 8 de la Ley 1700 de 2013, les confiere las siguientes:

- Realizar, de oficio o a solicitud de parte, visitas de inspección a las compañías multinivel y a sus puntos de acopio, bodegas y oficinas registradas, ejerciendo, de ser procedente, el principio de coordinación administrativa con otras autoridades para este fin.

- Revisar los libros de contabilidad de las compañías multinivel y exigirles aclaraciones sobre su información contable y su política de contabilización, incluidos los soportes, según sea necesario para el cumplimiento de sus funciones.

- Adelantar los procedimientos administrativos y sancionatorios previstos en esta ley, y los demás ya existentes y propios de su resorte con respecto a las compañías multinivel y sus actividades.

- Emitir órdenes de suspensión preventiva de todas o algunas de las actividades a determinada compañía multinivel, cuando cuente con evidencia que permita suponer razonablemente que este está ejerciendo actividades multinivel en sectores o negocios sin dar cumplimiento a los requisitos o exigencias legales, o contra expresa prohibición legal, o no está dando cumplimiento a cualquiera de las previsiones y requisitos establecidos dentro de esta ley, o en 'as normas que 'a modifiquen, complementen o desarrollen.

\subsection{CONCEPTO, NATURALEZA JURÍDICA Y DERECHOS DE LOS VENDEDORES INDEPENDIENTES}

Conceptualmente, se entenderá por vendedor independiente la persona natural comerciante o persona jurídica que ejerce actividades mercantiles, y que tiene relaciones exclusivamente comerciales con las compañías descritas de marketing multinivel o mercadeo en red.

El artículo 5 de la Ley 1700, dispone, además de los derechos que les confieran sus contratos 
y la ley, los vendedores independientes tendrán derecho a:

- Formular preguntas, consultas y solicitudes de aclaración a las compañías multinivel, quienes deberán contestarlas de manera precisa, antes, durante y después de su vinculación con el respectivo vendedor independiente. Estas deberán versar sobre los productos o servicios vendidos, o sobre el contenido, alcance $\mathrm{y}$ sentido de cualquiera de las cláusulas de los contratos que los vinculen con ellos, incluyendo toda información relevante relativa a las compensaciones o recompensas u otras ventajas de cualquier índole previstas en los contratos, y sobre los objetivos concretos cuyo logro dará derecho a los correspondientes pagos. Asimismo, sobre los plazos y fechas de pago o de entrega, cuando se trate de compensaciones en especie.

- Las respuestas a las preguntas, consultas, o solicitudes de aclaración de que trata el inciso anterior del presente numeral, deberán ser remitidas a la dirección, correo electrónico $u$ otros medios que suministren los vendedores independientes que las formulen, dentro de los plazos previstos en las normas vigentes para la respuesta a las peticiones de información.

- Percibir oportuna e inequívocamente de las compañías multinivel las compensaciones, o ventajas a los que tengan derecho en razón a su actividad, incluyendo las que hayan quedado pendientes de pago una vez terminado el contrato entre las partes.

- Conocer, desde antes de su vinculación, los términos del contrato que regirá su relación con la respectiva compañía multinivel, independiente de la denominación que el mismo tenga.

- $\quad$ Ser informado con precisión por parte de la compañía multinivel, de las características de los bienes y servicios promocionados, y del alcance de las garantías que correspondan a dichos bienes y servicios.

- Mediante escrito dirigido a la compañía multinivel, terminar en cualquier tiempo, y de forma unilateral, el vínculo contractual.

- Suscribirse como vendedor independiente de una o más compañías multinivelistas.

- Recibir una explicación clara y precisa sobre los beneficios a que tiene derecho por la inscripción a una compañía multinivel de forma que no induzca a confusión alguna.
- Recibir de la respectiva compañía multinivel, información suficiente y satisfactoria sobre las condiciones y la naturaleza jurídica del negocio al que se vincula con él como vendedor independiente, $\mathrm{y}$ sobre las obligaciones que el vendedor independiente adquiere al vincularse al negocio; al igual que sobre la forma operativa del negocio, sedes y oficinas de apoyo a las que puede acceder en desarrollo del mismo.

- Recibir de manera oportuna e integral en cantidad y calidad, los bienes y servicios ofrecidos por la compañía multinivel.

Cualquier cláusula del contrato que vincule a un vendedor independiente con una compañía multinivel, en la cual se prevea la renuncia a alguno de estos derechos o a otros que se establezcan en esta ley, o que impida su ejercicio, se considerará inexistente.

Dentro del costo inicial de participación, las compañías multinivel deberán incluir materiales de capacitación, así como referencias y guías de información en relación a cómo hacer el negocio, sobre una base no lucrativa.

\subsection{DE LOS REQUISITOS Y PROHIBICIONES DE LOS CONTRACTUALES EN EL MARKETING MULTINIVEL}

Los artículos 9 y 10 de la Ley 1700 instituyen una serie de requisitos mínimos y prohibiciones de los contratos que las compañías de marketing multinivel deben respetar para con sus vendedores o distribuidores independientes:

Las compañías multinivel deberán ceñir su relación comercial con los vendedores independientes a un contrato que deberá constar por escrito y contener como mínimo:

(i) Objeto del contrato; (ii) Derechos y obligaciones de cada una de las partes; (iii) Tipo de plan de compensación que regirá la relación entre las partes; (iv) Requisitos de pago; (v) Forma y periodicidad de pago; (vi) Datos generales de las partes. (vii) causales y formas de terminación; (vii) Mecanismos de solución de controversias; (viii) Dirección de la oficina u oficinas abiertas al público de la compañía multinivel. 
No se aceptarán direcciones web o virtuales o apartados aéreos como únicas indicaciones de correspondencia o localización de la compañía multinivel.

En lo atinente a las prohibiciones indicar que las compañías multinivel no podrán incluir en sus contratos los siguientes tipos de cláusulas:

- Cláusulas de permanencia y/o exclusividad.

- Cláusulas abusivas que generen desigualdad contractual.

- Obligación a los vendedores independientes sobre la compra o adquisición de un inventario mínimo, superior al pactado y aceptado previamente.

Además de lo anterior, queda prohibido desarrollar actividadescomerciales en la modalidad de Multinivel con los siguientes bienes y/o servicios:

- Servicios o productos cuya prestación constituya la actividad principal de cualquiera de las entidades sometidas a la vigilancia de la Superintendencia Financiera.

- Venta o colocación de valores, incluyendo tanto los que aparecen enumerados en la ley 964 de 2005, como todos los demás valores mediante los, cuales se capten recursos del público, o en los decretos emitidos con base en las facultades establecidas por la misma. En todo caso, se entenderá que primará la realidad económica sobre la forma jurídica al determinar si cualquier instrumento, contrato, bien o servicio que se ofrezca mediante actividades multinivel es, o no, un valor de naturaleza negociable.

- Servicios relacionados con la promoción y la negociación de valores.

- Alimentos altamente perecederos, u otros Que deban ser sometidos acuidados especiales para su conservación por razones de salubridad pública.

- Bienes o servicios Que requieran para su uso, aplicación o consumo, prescripción por parte de un profesional de la salud.

En el contexto de cuanto se está haciendo notar, resulta preciso destacar que la Ley 1700 , encuentra su desarrollo reglamentario, en el posterior Decreto 024 de 12 de enero de 2016, del Ministerio de Comercio, Industria y Turismo (2016).

El espíritu tanto de la Ley 1700 de 2013, como de su decreto reglamentario es claro, en tanto en cuanto buscará preservar los objetivos la trasparencia en las actividades multinivel; la buena fe; la defensa de los derechos de las personas que participen en la venta y distribución de los bienes o servicios que se comercialicen bajo este método y de los consumidores que los adquieran; la protección del ahorro del público y, en general, la defensa del interés público.

Que con el fin de cumplir con dichos objetivos, es necesario fijar requisitos en cuanto al beneficio económico que se puede percibir por la actividad; el conocimiento de las condiciones bajo las cuales se regirán las relaciones comerciales entre las sociedades y los vendedores independientes; la forma societaria que deben adoptar las empresas que desarrollan actividades de comercialización en red o mercadeo multinivel en Colombia y su representante comercial.

Resultan destacables las siguientes consideraciones y disposiciones que efectúa el Decreto 024, de 12 de enero:

\section{a. Sobre la compensación o beneficio económico}

El monto de la compensación o beneficio económico que la sociedad que realice actividades multinivel le pague al vendedor independiente, deberá guardar una relación causalidad directa con la venta de los bienes y servicios que sean objeto de la actividad de la sociedad.

El solo hecho vincular nuevas personas a la red comercial la actividad de multinivel no podrá lugar a beneficio económico o compensación de ninguna naturaleza aunque ella se realice por medio de reembolso.

\section{b. Sobre el conocimiento de los planes de compensación y condiciones contractuales}

Las sociedades que realicen la comercialización de sus productos o servicios en red o a través del mercadeo multinivel deben dar a conocer al vendedor independiente, manera previa a la firma del contrato, el contenido del plan de compensación, como todos los demás documentos en los cuales se incluyan condiciones que puedan el desarrollo la relación contractual, como códigos de ética, códigos de conducta, términos y 
condiciones o políticas de la sociedad. El plan de compensación deberá encontrarse a disposición de los vendedores independientes de manera permanente en la oficina abierta al público y en la página web de la sociedad.

\section{c. Sobre la compañía multinivel y el} representante comercial

Tanto las compañías que ofrezcan bienes o servicios en Colombia, a través de la comercialización en red o mercadeo multinivel, como los representantes comerciales que desarrollen esta actividad, deben ser sociedades mercantiles constituidas conformidad con la legislación colombiana. Las sociedades extranjeras pretendan desarrollar directamente en Colombia la actividad mercadeo multinivel, deberán establecer una sucursal en territorio colombiano. Las personas naturales no podrán ser representantes extranjeras que cumplan actividades de comercialización en red o mercadeo multinivel, ni realizar directamente dichas actividades en Colombia.

\section{d. Acerca de la potestad de suspensión inmediata de la actividad de comercialización en red o multinivel}

Cuando la Superintendencia, para proteger el ahorro público o defender el interés general, deba emitir la orden de suspensión preventiva de la actividad de mercadeo multinivel de cualquier empresa, esta se cumplirá de manera inmediata y se mantendrá hasta que la sociedad acredite haber subsanado los hechos que dieron origen a la suspensión. La medida preventiva se hará efectiva, sin perjuicio que se interpongan los recursos a que hubiere lugar durante su vigencia.

En el evento de que exista evidencia que le permita suponer razonablemente a la Superintendencia de Sociedades que los bienes o servicios comercializados o promovidos por una sociedad dedicada al mercadeo multinivel puedan encontrarse dentro de aquellos prohibidos por el artículo 11 de la Ley 1700 de 2013, la Superintendencia podrá ordenar la inmediata suspensión de la actividad.

e. Sobre las facultades administrativas de la superintendencia de sociedades

Cuando se advierta que a través de la actividad de comercialización en red o mercadeo multinivel se realizan operaciones de captación o recaudo sin la debida autorización estatal, la Superintendencia de Sociedades ejercerá de inmediato las facultades de intervención otorgadas por el Decreto 4334 de 2008.

\section{f. Vigilancia de la actividad multinivel}

La Superintendencia de Sociedades ejercerá la vigilancia de las sociedades comerciales y las sucursales de sociedades extranjeras que lleven a cabo la comercialización en red de sus productos o a través de los sistemas de mercadeo multinivel y de sus actividades, de conformidad con lo establecido en los artículos yo y $8^{\circ}$ de la Ley 1700 de 2013 y 82 a 87 de la Ley 222 de 1995.

En definitiva, todas las anteriores medidas contenidas tanto en la Ley 1700, como en el Decreto 024 que la desarrolla persiguen el objetivo de evitar que las empresas de venta directa multinivel o, si se prefiere, de mercadeo en red, hagan devenir sus esquemas empresariales en sistemas piramidales, y, en el caso de que así lo hagan, suspenderlos inmediatamente y proceder a llevar a las personas responsables antes los tribunales de justicia.

\section{EL DELITO DE CAPTACIÓN MASIVA Y HABITUAL DE DINEROS}

Resulta preciso hacer notar en primer término que las denominadas en Colombia como "actividades relacionadas con la captación y el manejo de ahorros del público" soportan una limitación constitucional que obliga a una previa autorización del Estado para acometer su ejercicio. El fundamento de dicha autorización es explicado por la Corte Constitucional de la siguiente forma:

(...) tales actividades comprometen el orden público económico y los intereses particulares de los usuarios, lo que exige garantizar la confianza en el sistema financiero. Además, por la importancia que reviste la actividad financiera dentro de un sistema de mercado, y por la necesidad de que sea prestada en forma permanente, continua, regular, general y en condiciones de igualdad para todos los usuarios, tal actividad ha sido calificada por la jurisprudencia de esta Corporación, de la Corte Suprema de Justicia y del Consejo de Estado como un servicio público (Corte Constitucional, 2013).

Es este el tratamiento jurídico penal específico que Colombia otorga a las estafas piramidales. 
En este orden de cosas y según comenta Álvarez Arboleda la actividad,

(...) la cual se relaciona inmediatamente con la captación masiva y habitual de dineros, y que se conoce comúnmente como "pirámide" consiste en pagar altísimos intereses a los clientes viejos a partir del dinero aportado por los nuevos. La idea inicial, a partir de la cual se entrega un rendimiento en proporción al dinero que consignen los ahorradores en la "empresa" y al tiempo que permanezca aquel en esta, no es nada diferente de la labor que realizan ciertas cooperativas, y es el principio de la actividad bancaria en general. No obstante, es la cantidad de intereses pagados la que genera que este comportamiento se constituya en un peligro para el bien jurídico, toda vez que es exponencialmente imposible mantener el flujo nuevo de personas que permitan cancelar con seguridad los intereses ofrecidos (2017: 267).

Sentado lo anterior, momento es ahora de indicar que la Corte Constitucional de Colombia ha situado al delito de captación en el ámbito del derecho penal económico al definir aquel en su Sentencia C-224 de 2009 como:

(...) el conjunto de normas jurídico penales que protegen el orden económico social, dando lugar i) a una concepción estricta, según la cual es el conjunto de normas jurídico penales que protegen el orden económico, entendido como regulación jurídica del intervencionismo estatal en la economía y ii) a una concepción amplia, como el conjunto de normas jurídico penales que protegen el orden económico, entendido como regulación jurídica de la producción, distribución y consumo de bienes y servicios (Corte Constitucional, 2009).

Al respecto, el artículo 316 del Código Penal Colombiano $^{6}$ (CP, en lo sucesivo), tipifica el delito de la siguiente manera:

(...) el que desarrolle, promueva, patrocine, induzca, financie, colabore, o realice cualquier otro acto para captar dinero del público en forma masiva y habitual sin contar con la previa autorización de la autoridad competente, incurrirá en prisión de ciento veinte (120) a doscientos

6. Vid., Ley 599 de 2000, Publicada en el diario oficial número 44.097 del 24 de julio de 2000, texto disponible al público en la página del Senado de la República de Colombia (dirección electrónica: http://www.secretariasenado.gov.co/senado/ basedoc/ley/2000/ley_0599_2000.html) cuarenta (240) meses y multa hasta de cincuenta mil (50.000) salarios mínimos legales mensuales vigentes. Si para dichos fines el agente hace uso de los medios de comunicación social u otros de divulgación colectiva, la pena se aumentará hasta en una cuarta parte (Congreso de la República de Colombia, 2000).

El hecho de tipificar "actos para la captación del dinero en forma masiva y habitual", ha llevado a SOTO NAVARRO (2003), citada por Arboleda a considerar que bien jurídico protegido en este tipo penal es de naturaleza colectiva, puesto que

(...) existe una sucesión de rasgos que permiten caracterizar a los bienes jurídicos colectivos, a partir de una serie de exigencias que por su naturaleza no pueden presentarse en los bienes de tipo individual. En primer lugar, menciona dicha autora la titularidad compartida por el conjunto de la sociedad, es decir, que los bienes colectivos pertenecen de manera exclusiva a la colectividad (2017: 246).

Finalmente debemos citar el hecho de que otro sector de la doctrina colombiana como considera que el delito de captación forma parte de los delitos contra el ordenamiento económico de Colombia, y protege un bien jurídico individual: el patrimonio (PABÓN PARRA, 2010).

Indicar que esta tipología de delitos se incardina dentro de lo que se viene a conocer en España como "delitos continuados", los cuales, siguiendo al profesor Muñoz Conde, para la existencia del delito continuado se exigen los siguientes elementos:

1) Objetivos: Homogeneidad del bien jurídico lesionado. Homogeneidad de los modos de comisión del delito. Cierta conexión espacial y temporal.

2) Subjetivos: La presencia de un dolo conjunto o designio criminal común a las diversas acciones realizadas. Originariamente, el delito continuado fue una institución que surgió con objeto de beneficiar al reo, al excluir sus diversas acciones delictivas de las reglas del concurso real, valorándolas como una sola o por lo menos como un solo delito (Muñoz Conde, 2010).

Sea como fuere su naturaleza jurídica lo verdaderamente importante, en opinión del articulista, de este tipo penal que tipifica y castiga 
las estafas piramidales es que se trata, a diferencia de otros países (como es el caso de España), de un tipo penal específico, aspecto este de gran relevancia por cuanto permite un accionar directo de la justicia que agiliza y facilita la acción de los organismos del Estado a cargo de impartirla (FERNANDEZ-SALINERO, 2019).

\section{LAS ESTAFAS PIRAMIDALES Y LA CRIPTOMONEDA: SU TRASCENDENCIA JURÍDICO PENAL}

Actualmente es un hecho común que las diferentes criptomonedas (Bitcoin; Ethereum; Litecoin, entre otras) vienen a ser un medio de pago, o incluso de especulación e inversión, por parte de las personas que tradicionalmente se dedican a la Venta Directa Multinivel (que, como se ha visto, muchas veces deviene en un sistema piramidal).

Por ello, en los últimos tiempos se han presentado situaciones de personas que han sido estafadas en sistemas piramidales, siendo utilizada la criptomoneda como centro neurálgico de la estafa, por el hecho de ser creada directamente para cometerla, o bien porque el sujeto estafado ha utilizado la criptomoneda para abonar el importe de las licencias de acceso a un determinado entramado piramidal.

En aras de un correcto entendimiento de este bloque, vamos a ocuparnos ahora de algunas cuestiones terminológicas que resulta menester comprender, así como del tratamiento fiscal de las distintas operaciones con criptomonedas, antes de centrarnos en los supuestos concretos.

\subsection{EL CONCEPTO DE CRIPTOMONEDA}

Una criptomoneda, criptodivisa o criptoactivo (por ejemplo el Bitcoin) es un bien inmaterial mueble, digital, no fungible ${ }^{7}$, en forma de documento electrónico, susceptible de propiedad privada y gestionado informáticamente a través de clave pública y privada, descentralizadamente, sin autoridad de emisión o control, apoyada en red de distribución persona a persona, a través de nodos interconectados (ordenadores) que verifican

7. En el sentido que en las transacciones se utilizan algoritmos y códigos de rastreo para cada moneda, por lo que existe la posibilidad de hacer un rastreo detallado de cada criptomoneda en específico asociado a determinadas cuentas y finalmente llegar a los usuarios reales de las monedas. colectivamente las transferencias y ponen en conocimiento de los demás que la validan.

No es por tanto la criptomoneda un activo tangible, ya que su naturaleza es completamente descentralizada, esto es, no tiene el sustento, cobertura, autorización ni control por parte de ningún Banco Central.

La criptomoneda más famosa, y la primera en comenzar a operar desde el año 2009 es el Bitcoin. $\mathrm{Su}$ creación se atribuye a "Satoshi Nakamoto", quien publicó en el año 2008 un artículo en la lista de criptografía de metzdowd.com donde describe el protocolo Bitcoin.

Desde entonces son muchas otras las criptodivisas que han ido apareciendo, y cada una con características diferentes que se establecen ya desde su programación. Algunas de ellas son Litecoin, Ethereum, Ripple, Monero, Dash.

En los sistemas de criptomonedas se garantiza la seguridad, integridad y equilibrio de sus estados de cuentas por medio de un entramado de agentes que se verifican mutuamente llamados mineros. Son, en su mayoría, público en general que aporta potencia computacional y que protegen activamente la red al mantener una alta tasa de procesamiento de algoritmos, con la finalidad de tener la oportunidad de recibir una pequeña propina, que se reparte de manera aleatoria. De manera sencilla, son personas que aportan sus ordenadores o incluso dispositivos móviles, para resolver complejos problemas matemáticos en forma de algoritmos y que reciben, de forma aleatoria, como recompensa, una parte de criptomoneda.

Las criptomonedas hacen posible el llamado internet del valor, aplicaciones de Internet que permiten el intercambio de valor en la forma de criptomonedas. Este valor puede estar representado en contratos, propiedad intelectual, acciones o en general cualquier propiedad de algo que tenga contraprestación económica. Las cosas de valor ya se podían intercambiar antes usando sistemas de pago como Paypal, sin embargo, la diferencia entre este sistema y la criptomoneda consiste en que Paypal requiere que el pago se haga a través de redes privadas como las de las

8. En la actualidad no se conoce con exactitud quien o que es Satoshi Nakamoto. 
tarjetas de crédito y bancos, mientras que el pago usando criptomonedas no tiene intermediarios. Va directamente del comprador al vendedor. De esta forma se tiene un sistema de transferencia universal de valor libre de intermediaciones.

Además, el propietario de un bitcoin es el encargado de dejar constancia de la transacción, mediante un pseudónimo, en el libro contable público y descentralizado denominado Blockchain, que permite garantizar la seguridad y transparencia de la operación financiera.

En la actualidad son muchas las empresas y pequeños comerciantes que aceptan bitcoins como medio de pago de bienes y servicios diversos, tales como telefonía, , tarjetas regalo, asesoría legal, turismo, etc.

Ciertamente, su ámbito internacional y el hecho de que los usuarios pueden comerciar con un cierto anonimato, ha hecho posible que se abra paso en sectores cada vez más regulados, como apuestas en línea y partidas de póker.

Algunos ejemplos de multinacionales que aceptan el BTC como medio de pago son Microsoft, Dell, Time Inc. y Dish Network, que. Por su parte, Paypal anunció en septiembre de 2014 que ha comenzado a preparar su sistema para aceptarlos.

En el año 2011, Wikileaks solicitó apoyos en BTC tras el bloqueo orquestado por los procesadores de pago electrónico Visa, MasterCard y PayPal. Asimismo, varias organizaciones, como la Fundación Wikimedia, Fundación Mozilla, Internet Archive, Free Software Foundation, Freenet, ElectronicFrontierFoundation y otras más, aceptan actualmente donaciones en BTC.

\subsection{EL CONCEPTO DE BLOCKCHAIN}

El Blockchain, también denominado "Contabilidad Distribuida y Pública", es una tecnología que permite la realización confiable y segura de cualquier tipo de transacción entre dos o más personas sin la necesidad de intermediarios, a través de Internet. Su introducción al mundo se dio a través del BTC, que es la primera plataforma blockchain. Originalmente, Bitcoin se creo como un sistema electrónico de pago entre pares, por lo que se le conoce como "dinero digital".
Blockchain es una articulación de tecnologías estructuradas en un sistema naturalmente encriptado, lo que proporciona a los usuarios involucrados protección de sus identidades y de los datos de sus transacciones.

Es, básicamente, como un libro de contabilidad digital donde se anotan todas las transacciones que suceden en la red, agrupadas en bloques que continuamente son enlazados linealmente entre sí, esto es: el primer bloque con el segundo, el segundo con el tercero, y así sucesivamente.

También es importante conocer qué son las CARTERAS DIGITALES, siendo estas interfaces gráficas para interactuar con la red blockchain que permiten a los usuarios realizar transacciones y manejar sus identidades digitales.

La tecnología blockchain garantiza que los registros de las transacciones realizadas sean válidos e inalterables. Esto no es otra cosa que la INMUTABILIDAD del BTC. Podemos ver cada bloque como cada una de las páginas de un mismo libro contable prácticamente infinito, sólo que aquí lo que ha sido escrito no puede borrarse ni repetirse: cada transacción o dato se resguarda con una huella digital única. Blockchain tampoco puede ser hackeado.

Como características esenciales del blockchain se citan las siguientes:

- $\quad$ Es una red descentralizada para intercambio de activos (sistema distribuido entre iguales)

- Utiliza un controlador compartido (público o privado)

- Registra un histórico de transacciones electrónicas en una red entre iguales (P2P)

- Garantiza un sellado digital de tiempo (time stamping), mediante método (funciones hash) que verifica su corrección y permite a tercero impugnar su validez, así como el hecho de que cualquier dato o transferencia no ha sido alterada.

- Registra las transacciones a modo de libro de contabilidad pública en bloques o cadenas de datos ordenados y conectados.

- Utiliza tecnologías criptográficas y de ciberseguridad en aras a alcanzar y mantener la integridad de la información.

- Cada transacción que se completa, se muestra cronológicamente en un bloque. Cada bloque se une a otros bloques que forman la cadena. 
Se puede AFIRMAR que las criptomonedas son la unidad monetaria de las transacciones realizadas a través de blockchain.

\subsection{EL CONCEPTO DE TOKEN}

De acuerdo con Mougayar, 2016, un token es "una unidad de valor" que una organización crea para gobernar su modelo de negocio y dar más poder a sus usuarios para interactuar con sus productos, al tiempo que facilita la distribución y reparto de beneficios entre todos sus accionistas.

\subsection{EL RÉGIMEN JURÍDICO DE LAS CRIPTODIVISAS Y CRIPTOACTIVOS EN EL ORDENAMIENTO JURÍDICO ESPAÑOL}

Juridicamente criptodivisas y criptoactivos no tienen la consideración de dinero electrónico, puesto que se encuentran reconocidas como tal en la Ley $21 / 2011$, de 26 de julio de dinero electrónico («BOE» núm. 179, de 27 de julio de 2011, páginas 84235 a 84254.

Tampoco puede decirse que tengan la consideración de valor, porque no tienen esa cualidad jurídica en la Ley 24/1988 del Mercado de Valores, la cual no hace siquiera referencia a las criptovisas o criptoactivos.

Por lo tanto, aunque no son dinero electrónico, nuestro ordenamiento jurídico no prohíbe la utilización de las mismas como medio de pago y como sistema de inversión.

De una manera técnico-jurídica, las criptodivisas y criptoactivos deben considerarse como un bien mueble, de naturaleza digital susceptible de ser de propiedad privada, caracterizado por su condición de bien fungible.

Las criptodivisas y criptoactivos puede transmitirse mediante su utilización como medio de pago en operaciones de compraventa, a través de alguna de las plataformas dedicadas a su comercialización (ejemplo COINBASE, COIN MARKET CAP, entre otras), o bien en contratos de permuta (cambio de cosa por cosa).

Indicar en este momento que en la actualidad no existe en España una regulación jurídica expresa y específica relativa a las criptodivisas y criptoactivos, aunque no es menos cierto que el Parlamento Europeo esta gestando en la actualidad una regulación normativa que vendrá a reglamentar esta materia, la cual deberá ser incorporada a los ordenamientos jurídicos de los Estados Miembros de la Unión Europea. De momento resultar menester observar la Resolución el Parlamento Europeo sobre monedas virtuales a la que nos vamos a remitir 9 .

En primer lugar hay que diferenciar el uso que se le da al bitcóin o a cualquier criptomoneda:

- Criptomonedas como moneda de pago: la Unión Europea considera las criptomonedas como el Bitcoin un medio de pago y en España desde el año 2015 se considera un medio de pago legal. Por tanto, se aplica el IVA en cualquier compra de bienes o servicios pero no se aplica el IVA en la transmisión de la moneda.

- Criptomonedas como inversión: en el que caso de que usemos las criptomonedas como inversión a través de un broker y tengamos ganancias o pérdidas, este resultado se tendrá que incorporar a nuestro IRPF y pagar impuestos por ello.

En cuanto a la criptodivisa como medio, cabe indicar que el Código Civil español establece en su artículo 1445 lo siguiente:

Por el contrato de compra y venta uno de los contratantes se obliga a entregar una cosa determinada y el otro a pagar por ella un precio cierto, en dinero o signo que lo represente (Subrayas fuera del original) (Ministerio de Gracia y Justicia, 1889).

Pues bien, ese "signo que lo represente" (al dinero) puede ser una criptodivisa, ya que en el fondo y en la forma representa al dinero. Esta es una opinión del articulista, siempre sometida a otra mejor fundada en Derecho.

\section{CONCLUSIONES}

Como puede inferirse en méritos de cuanto queda expuesto, la legislación de Colombia en materia de marketing multinivel o, si se prefiere, mercadeo en red, puede y debe ser un ejemplo para los legisladores de todo el mundo, ya que no

9. Vid., Resolución del Parlamento Europeo, de 26 de mayo de 2016, sobre monedas virtuales (2016/2007(INI)) 
resulta de recibo el hecho de que en la mayoría de los países del mundo, entre los que se incluye España, no existe una legislación que instituya una regulación específica de las actividades de venta directa multinivel.

Esta indeseable ausencia de legislación de la materia trae consigo graves consecuencias, como la existencia de vacíos legales que redundan muchas veces en la impunidad de las personas responsables de atroces estafas piramidales.

La legislación estudiada muestra que la especificidad del trato al tipo penal, permitirá a la administración de justicia un mejor y más ágil manejo del delito en cuestión. En el mismo sentido permitirá a las personas del común una protección especial contra este tipo de estafa al brindar herramientas efectivas al Estado para intervenir a tiempo cuando se presenten los supuestos de hecho que concurren para la comisión del delito.

Esta investigación insta a los legisladores del mundo a que revisen la Ley 1700 de 2013, así como su desarrollo reglamentario en el Decreto 024 de 2016, en orden a establecer en cada país una legislación adecuada que sirva para disuadir la creación de sistemas piramidales de venta directa, evitando de este modo consecuencias asoladoras para las personas que invierten sus ahorros en dichos infames esquemas.

\section{BIBLIOGRAFÍA}

- Alvarez Arboleda, J.F. (2017). El delito de captación masiva y habitual de dineros en el ordenamiento penal colombiano, Nuevo Foro Penal 13 (88), 240 - 271.

- Bedoya, J. (2009). La pirámide de David Murcia. Bogotá: Ed. Planeta.

- Diaz, L. (2014). EL CASO DMG: responsabilidad del Estado susceptible de indemnización por acción de grupo. Revista Derecho y Realidad 12 (24), 257-278. Doi: https://doi.org/10.19053/16923936. v2.n24.2014.4522

- Fernandez-Salinero, M. A. (2019). Las Estafas Piramidales y su trascendencia jurídico penal. Madrid: Dykinson S.L.

- Muñoz Conde, F. y García Arán, M. (2010). Derecho Penal Parte General. Valencia: Tirant Lo Blanch.

- Mougayar, W. (2016). The Business Blockchain: Promise, Practice, and Application of the Next Internet Technology. Washington: Wiley.

- Pabón Parra, P.A. (2010). Manual de Derecho Penal: Parte especial. Bogotá: Ediciones Doctrina y Ley.

- Soto Navarro, S. (2003). La protección penal de los bienes colectivos en la sociedad moderna. Granada: Comares.

\section{NORMAS RESOLUCIONES Y SENTENCIAS CITADAS}

\section{Colombia}

- Congreso de la República de Colombia. (2000). Ley 599 de 2000, CÓDIGO PENAL COLOMBIANO. Diario oficial número 44.097 del 24 de julio de 2000.

- ----. (2013). LEY 1700 DE 27 DE DICIEMBRE DE 2013, "por medio de la cual se reglamentan las actividades de comercialización en red o mercadeo multinivel". Diario Oficial 49016 de diciembre 27 de 2013.

- Corte Constitucional. (2009). Sentencia C-224 de 2009. M.P.: Jorge Iván Palacio Palacio.

- --- (2013) Sentencia C-1062 de 2013. M.P.: Marco Gerardo Monroy Cabra.

- Ministerio de Comercio, Industria y Turismo. (2016) DECRETO 024 DE 12 DE ENERO DE 2016, "el cual adiciona un capítulo al título 2 de la parte 2 del libro 2 del Decreto Único Reglamentario del Sector Comercio, Industria y Turismo, número 1074 de 2015, y se dictan otras disposiciones". 


\section{España}

- Audiencia Nacional Española. (2017). AUTO AN de 16/01/2017, Sección 5ạ; №. Recurso: 112/2011 Numroj: AAN 3/2017 Ecli: ES:AN:2017:3‥

- Jefatura del Estado. (1991). Ley 3/1991, de 10 de Enero, de Competencia Desleal.

- «BOE» núm. 10, de 11 de enero de 1991. Referencia: BOE-A-1991-628

- $\quad$--- (1996). LEY 7/1996, DE 15 DE ENERO, de ordenación del comercio minorista.

- «BOE» núm. 15, de 17 de enero de 1996. Referencia: BOE-A-1996-1072.
- $\quad$ Ministerio de Gracia y Justicia. (1889). Real Decreto de 24 de julio de 1889 por el que se publica el Código Civil. «Gaceta de Madrid» núm. 206, de 25/07/1889.

- Tribunal Supremo Español. (2014) STS de fecha 26/12/2014; №. de Recurso 949/2014; nº. de Resolución 900/2014.

\section{Parlamento Europeo}

- Parlamento Europeo. (2016). Resolución de 26 de mayo de 2016, sobre monedas virtuales. 